\title{
Determination of Association of Hyperchloremia with Rise in Inflammatory Markers, Serum Creatinine and Anaemia in COVID-19 Patients in Intensive Care Unit - A Prospective Follow-up Study
}

\author{
Vedaghosh Amara', Souvik Chaudhuri ${ }^{2}$, Arjun $N^{3}$, Shwethapriya Rao ${ }^{4 *}$, Vishwas P $^{5}$ \\ ${ }^{1}$ Asian Institute of Gastroenterology, Hyderabad, ${ }^{2,3,4,5}$ Kasturba Medical College, Manipal, \\ Manipal Academy of Higher Education
}

\begin{abstract}
Hyperchloremia leads to adverse effects like increase in pro-inflammatory mediators, anaemia and renal dysfunction. Aim of this study is to determine the association of hyperchloremia with rise in C-reactive protein (CRP), serum ferritin, lactate dehydrogenase (LDH), serum creatinine and anaemia in COVID-19 patients in intensive care unit (ICU). It was a single-centre study, 62 COVID-19 patients participated. Change in CRP, serum ferritin, LDH, serum creatinine, haemoglobin between day one and day three of ICU admission were noted. Outcome in terms of in-hospital mortality was noted. Hyperchloremia $(>106 \mathrm{mmol} / \mathrm{L})$ or rise in chloride by $>5 \mathrm{mmol} / \mathrm{L}$ was seen in $13 / 62$ (20.96\%) patients. It was not associated with a rise in CRP, ferritin, LDH, creatinine, drop in hemoglobin within 72 hours or in-hospital mortality. 44/62 (71\%) patients survived and were discharged from hospital. Multivariate logistic regression showed that if age and gender are also considered, there is a 25 times higher chance of having had a significant ferritin rise (> $95 \mathrm{ng} / \mathrm{mL})$ in 72 hours of ICU admission among those who died. $(\mathrm{p}=0.01)$. Hyperchloremia $(>106 \mathrm{mmol} / \mathrm{L})$ or a rise in chloride by $>5 \mathrm{mmol} / \mathrm{L}$ in 72 hours of ICU admission was not associated with a significant increase in CRP, LDH, ferritin, serum creatinine within 72 hours of ICU admission or mortality in moderate-severe COVID-19 patients. If age and gender are taken into consideration, there is a 25 times higher chance of having had a significant ferritin rise (> $95 \mathrm{ng} / \mathrm{mL})$ in 72 hours of ICU admission among those who died.
\end{abstract}

Key words: COVID-19, hyperchloremia, ferritin rise, C-Reactive Protein rise, mortality

\section{Introduction}

Hyperchloremia has deleterious effects in critically ill, like accentuation of metabolic acidosis and inflammatory process, hemodynamic instability, acute kidney injury, and anaemia. ${ }^{1,2}$ Hyperchloremia, defined as serum chloride level >106-111 $\mathrm{mmol} / \mathrm{L}$, according to laboratory values. ${ }^{3}$ At our institute, it is compatible with a chloride level $>106$ $\mathrm{mmol} / \mathrm{L} .{ }^{3}$ Hyperchloremic acidosis augments

*Correspondence: Shwethapriya Rao
E mail: shwethapriya.rao@manipal.edu

https://orcid.org/0000-0002-5635-5332

Received: 01/07/2021

Accepted: 26/09/2021

DOI: https://doi.org/10.4038/slja.v29i2.8882 pro-inflammatory mediators, interleukin -6 (IL$6)$, IL-10 via the nuclear factor k-beta (NF-kB) pathway. ${ }^{1,4} \mathrm{NF}-\mathrm{kB}$ leads to $\mathrm{C}$-reactive protein (CRP) rise. ${ }^{5} \mathrm{CRP}$, ferritin and lactate dehydrogenase $(\mathrm{LDH})$ are important prognostic mediators in patients with COVID-19.6,7 We conducted this study to determine association of hyperchloremia or a 72 hour rise in chloride level with a 72 hour rise in CRP, ferritin and LDH in moderate-severe COVID-19 patients, and to assess if serum chloride can serve as a surrogate of these expensive markers in resource limited settings. We also evaluated the association between rise in inflammatory markers in the initial 72 hours with mortality. To the best of our knowledge, similar study has not been done.

\section{Methods}

It was a single centre observational study over a period of six months. It was conducted as a pilot study, after obtaining clearance from institutional ethics committee (IEC558/2020) and CTRI 
registration (CTRI/2020/11/029060). Moderate to severe COVID-19 patients admitted to the intensive care unit (ICU) were enrolled in the study. The following definitions have been used in selecting patients with moderate and severe COVID-19. ${ }^{8}$

Moderate disease: Patients with symptoms or radiologic features of lower respiratory tract disease and who have oxygen saturation $\left(\mathrm{SpO}_{2}\right) \geq$ $94 \%$ on room air. ${ }^{8}$

Severe disease: Patients who have $\mathrm{SpO}_{2} \leq 94 \%$ on room air, tachypnoea with respiratory rate $>30$ breaths/min or lung infiltrates being $>50 \%{ }^{8}$

\section{Inclusion criteria:}

1. Moderate to severe COVID-19 patients with positive Reverse -Transcription-Polymerase Chain Reaction (RT-PCR) test.

2. Patients aged between $18-80$ years

\section{Exclusion criteria:}

1. Patients with upper gastro-intestinal bleed, malaena, haematuria, petechiae or evidence of hematoma on skin.

2. Chloride $>106 \mathrm{mmol} / \mathrm{L}$ on admission.

3. Patient with diagnosed chronic kidney disease (CKD).

4. Patient with acute kidney injury on admission as defined by RIFLE criteria. ${ }^{9}$

5. Patient on haemodialysis or peritoneal dialysis.

6. Patient on any carbonic anhydrase inhibitor acetazolamide, methazolamide, dorzolamide, ethoxzolamide.

7. Patients with proven bacterial/fungal infections as per culture reports.

Age, gender, Acute Physiology and Chronic Health Evaluation (APACHE II), Sequential Organ Failure Assessment (SOFA) and haemoglobin $(\mathrm{Hb})$, serum creatinine, chloride level on day of admission were noted. Arterial blood sample was used to evaluate chloride levels. ABG analysis machine ABL 800 FLEX blood gas analyser (Radiometer, Copenhagen, Denmark) was used to analyse chloride level after calibration. Chloride estimation using ABG analyser was considered satisfactory. ${ }^{10,11}$ Chloride level, CRP, serum ferritin, LDH, haemoglobin $\mathrm{Hb}$ and serum creatinine levels were noted on day one and day three of ICU admission and the difference between the respective levels was noted. Serum chloride $>106 \mathrm{mmol} / \mathrm{L}$, either on day one or day three was defined as hyperchloremia. ${ }^{3}$ Rise in chloride was taken as an increase by $>5 \mathrm{mmol} / \mathrm{L}$ between day one and day three. ${ }^{12}$ Similarly a rise between day one and day three of CRP, ferritin, LDH and creatinine was considered as increase by $>10 \mathrm{mg} / \mathrm{L},>95 \mathrm{ng} / \mathrm{mL}$, $>238 \mathrm{U} / \mathrm{L}$ and $>0.3 \mathrm{mg} / \mathrm{dL}$ respectively. ${ }^{13}$ A drop in $\mathrm{Hb}$ between day one and day three in ICU was considered as $>0.5 \mathrm{~g} / \mathrm{dL} .{ }^{14}$

The methodology of the study is depicted in flowchart (Figure 1).

This was conducted as a pilot study over a period of six months, with consecutive sampling process. All moderate-severe COVID-19 patients who were admitted to the intensive care unit and were eligible as per inclusion and exclusion criteria were recruited. However, with the prevalence of high CRP and hyperchloremia being $57 \%$ as per our results, the post-hoc analysis was done. It showed that with an alpha error of 5\%, the sample size 62 had $22 \%$ precision.

Data analysis was done using statistical software IBM SPSS (Statistical Package for the Social Sciences) software (IBM Corp. Released 2012.IBM SPSS statistics for Windows, version 22.0 Armonk, NY: IBM). Continuous variables were analysed as mean and standard deviation or median and interquartile range (IQR). Correlation between qualitative data was done using Pearson Chi-square test. A $p$ value of $<0.05$ was considered significant. Analysis of whether the data was skewed or not was done by Shapiro Wilk test. Univariate and then multivariate analysis logistic regression was done for APACHE II score, SOFA score, hyperchloremia, anaemia, $\mathrm{AKI}$, increased CRP, ferritin, LDH to predict mortality. Hosmer and Lemeshow goodness of fit test for logistic regression was done. 
Haemoglobin, serum creatinine, highest value of chloride from ABG on day 1 of ICU stay was noted along with CRP, ferritin, LDH.

Haemoglobin, serum creatinine, highest value of chloride from ABG on day 3 of ICU stay was noted along with CRP, ferritin, LDH.

Rise of chloride, CRP $(>10 \mathrm{mg} / \mathrm{L})$, ferritin $(>95 \mathrm{ng} / \mathrm{mL}), \mathrm{LDH}(>238 \mathrm{U} / \mathrm{L})$, creatinine $(>0.3 \mathrm{mg} / \mathrm{dL})$ and drop in hemoglobin $(>0.5 \mathrm{~g} / \mathrm{dL})$ between day one and day three was noted.

Outcome of patients in terms of in-hospital mortality was noted.

Statistical analysis done to evaluate association of hyperchloremia or a rise in chloride between day one and day three of ICU stay to rise in CRP, ferritin, LDH, creatinine and drop in hemoglobin during the same period.

Figure 1. Flow chart depicting methodology

Table 1: Association of hyperchloremia $(>106 \mathrm{mEq} / \mathrm{L})$ and rise in inflammatory markers

(CRP, ferritin and LDH) in the moderate-severe COVID-19 patients

\begin{tabular}{|c|c|c|c|c|c|c|}
\hline \multirow{3}{*}{\multicolumn{2}{|c|}{$\begin{array}{l}\text { Parameter rise } \\
\text { between day one and } \\
\text { day three }\end{array}$}} & \multicolumn{4}{|c|}{$\begin{array}{l}\text { Chloride }>106 \mathrm{mEq} / \mathrm{L} \\
\text { (either on day one or day three of ICU stay) }\end{array}$} & \\
\hline & & \multicolumn{2}{|c|}{ No } & \multicolumn{2}{|c|}{ Yes } & \\
\hline & & Count & Column N \% & Count & Column N \% & P value * \\
\hline \multirow[t]{2}{*}{ CRP rise } & No & 41 & $74.5 \%$ & 3 & $42.9 \%$ & \multirow[t]{2}{*}{0.08} \\
\hline & Yes & 14 & $25.5 \%$ & 4 & $57.1 \%$ & \\
\hline \multirow[t]{2}{*}{ Ferritin rise } & No & 37 & $69.8 \%$ & 3 & $50.0 \%$ & \multirow[t]{2}{*}{0.3} \\
\hline & Yes & 16 & $30.2 \%$ & 3 & $50.0 \%$ & \\
\hline \multirow[t]{2}{*}{$\mathrm{LDH}$ rise } & No & 40 & $83.3 \%$ & 2 & $50.0 \%$ & \multirow[t]{2}{*}{0.1} \\
\hline & Yes & 8 & $16.7 \%$ & 2 & $50.0 \%$ & \\
\hline
\end{tabular}

$\mathrm{P}$ value $<0.05$ is considered significant, $*$ Statistical test used for analysis- Pearson Chi-square test. 


\begin{tabular}{|l|c|}
\hline $\begin{array}{l}\text { Table 2: Univariate analysis of the parameters in the study to outcome in terms of } \\
\text { in-hospital mortality }\end{array}$ & $\begin{array}{c}\text { Relation to outcome in terms of } \\
\text { mortality (P value) }\end{array}$ \\
\hline Parameters in the study & 0.4 \\
\hline Hyperchloremia $(>106 \mathrm{mmol} / \mathrm{L})$ & 0.6 \\
\hline Rise in chloride $(>5 \mathrm{mmol} / \mathrm{L})^{*}$ & 0.1 \\
\hline Drop in $\mathrm{Hb}(>0.5 \mathrm{~g} / \mathrm{dL})^{*}$ & 0.09 \\
\hline Rise in CRP $(>10 \mathrm{mg} / \mathrm{L})^{*}$ & $<\mathbf{0 . 0 5}$ \\
\hline Rise in ferritin $(>95 \mathrm{ng} / \mathrm{mL})^{*}$ & 0.7 \\
\hline Rise in LDH $(>238 \mathrm{U} / \mathrm{L})^{*}$ & $<\mathbf{0 . 0 5}$ \\
\hline Rise in creatinine $(>0.3 \mathrm{mg} / \mathrm{dL})^{*}$ & \\
\hline${ }^{*}$ Rise between day one and day three of ICU admission \\
${ }^{* *}$ Indicates that P value is statistically significant
\end{tabular}

\begin{tabular}{|c|c|c|c|c|}
\hline Parameters & $\mathrm{P}$ value & OR & $\begin{array}{l}95 \% \text { CI for OR } \\
\text { Lower }\end{array}$ & $\begin{array}{l}\text { 95\% CI for OR } \\
\text { Upper }\end{array}$ \\
\hline APACHE II score & 0.23 & 1.099 & 0.941 & 1.285 \\
\hline SOFA score & 0.15 & 1.329 & 0.899 & 1.964 \\
\hline Rise in CRP $(>10 \mathrm{mg} / \mathrm{L})^{*}$ & 0.74 & 0.712 & 0.095 & 5.321 \\
\hline Rise in ferritin $(>95 \mathrm{ng} / \mathrm{mL})^{*}$ & $<0.05^{* *}$ & 7.044 & 1.207 & 41.117 \\
\hline Rise in LDH $(>238 \mathrm{U} / \mathrm{L})^{*}$ & 0.23 & 0.192 & 0.013 & 2.857 \\
\hline $\begin{array}{l}\text { Rise in creatinine } \\
(>0.3 \mathrm{mg} / \mathrm{dL})^{*}\end{array}$ & 0.87 & 0.803 & 0.051 & 12.614 \\
\hline Rise in chloride $(>5 \mathrm{mmol} / \mathrm{L})^{*}$ & 0.58 & 0.434 & 0.022 & 8.433 \\
\hline \multicolumn{5}{|c|}{$\begin{array}{l}{ }^{*} \text { Rise between day one and day three of ICU admission } \\
{ }^{* *} \text { Indicates that } \mathrm{p} \text { value is significant } \\
\text { OR - Odd's ratio, CI - Confidence Interval }\end{array}$} \\
\hline
\end{tabular}

\section{Results}

Among the 62 patients, 15 were females and 47 were males. The mean and standard deviation (SD) of age was $55.7 \pm 14$ years. The mean and SD of APACHE II score of survivors was 9.86 and 6.94, and non-survivors was 17.72 and 9.14 respectively. The mean and SD of SOFA score of survivors were 4.09 and 2.25, and non-survivors were 6.72 and SD 4.04. Eight patients had increase in chloride level $>5 \mathrm{mmol} / \mathrm{L}$ in 72 hours and seven patients had chloride level $>106 \mathrm{mmol} / \mathrm{L}$ (hyperchloremia) either on day one or day three of ICU stay. Either hyperchloremia or rise in chloride was seen in 13/62 (20.96\%) patients. The number of patients who had a rise in CRP (>10mg/L), ferritin (> 95ng/mL) and LDH ( $>238 \mathrm{U} / \mathrm{L}$ ) between day one and day three was 18
(29\%), 19 (30.6\%) and 10 (16.12\%) respectively. 28 patients had a drop in haemoglobin $>0.5 \mathrm{~g} / \mathrm{dL}$. Nine patients had a rise in serum creatinine $(>0.3 \mathrm{mg} / \mathrm{dL})$. Hyperchloremia $(\mathrm{Cl}>106 \mathrm{mmol} / \mathrm{L})$ was not associated with a rise in CRP, ferritin or LDH (Pearson Chi-square test, $\mathrm{p}=0.08,0.3$ and 0.1 respectively) (Table 1 ).

Univariate analysis of different variables of the study and mortality was done (Table 2). The multivariate logistic regression without taking age and gender into account of the different parameters to mortality was performed (Table 3 ). Likewise, a rise in serum chloride $(>5 \mathrm{mmol} / \mathrm{L})$ between day one and day three was not associated with rise in CRP, ferritin or LDH in 72 hours (Pearson Chi-square test, $\mathrm{p}=0.681,0.197$ and 0.242 respectively). 
Table 4: The multivariate logistic regression after taking age and gender into account of the different parameters to mortality

\begin{tabular}{|l|c|c|c|c|}
\hline Parameters & P value & OR & $\begin{array}{c}95 \% \text { CI for } \\
\text { OR } \\
\text { Lower }\end{array}$ & $\begin{array}{c}95 \% \text { CI for } \\
\text { OR } \\
\text { Upper }\end{array}$ \\
\hline Age & 0.108 & 1.086 & 0.982 & 1.200 \\
\hline Gender (Male) & 0.099 & 0.134 & 0.012 & 1.461 \\
\hline APACHE II score & 0.669 & 1.039 & 0.873 & 1.236 \\
\hline SOFA score & 0.159 & 1.389 & 0.879 & 2.196 \\
\hline Chloride rise (>5mmol/L) & 0.296 & 0.166 & 0.006 & 4.836 \\
\hline Rise in CRP $(>10 \mathrm{mg} / \mathrm{L})^{*}$ & 0.463 & 2.394 & 0.233 & 24.588 \\
\hline Rise in ferritin $(>95 \mathrm{ng} / \mathrm{mL}) *$ & $<\mathbf{0 . 0 5}$ & $\mathbf{2 5 . 7 1}$ & $\mathbf{2 . 1 9 8}$ & $\mathbf{3 0 0 . 7 4 4}$ \\
\hline Rise in LDH $(>238 \mathrm{U} / \mathrm{L}) *$ & 0.164 & 0.156 & 0.011 & 2.140 \\
\hline Rise in creatinine (>0.3mg/dL)* & 0.893 & 1.230 & 0.061 & 24.750 \\
\hline${ }^{*}$ Rise between day one and day three of ICU admission \\
*** Indicates that p value is significant \\
OR - Odd's ratio, CI - Confidence Interval
\end{tabular}

Hyperchloremia was not associated with rise in serum creatinine ( $\mathrm{p}=0.8$, Mann-Whitney $\mathrm{U}$ test). Hyperchloremia was not associated with drop in $\mathrm{Hb}$ (Pearson Chi-square test, $\mathrm{p}=0.2$ ), and rise in chloride level by $>5 \mathrm{mmol} / \mathrm{L}$ in 72 hours was also not associated with drop in $\mathrm{Hb}$ (Pearson Chisquare test, $\mathrm{p}=0.3$ ). If age and gender are not considered, there is a seven times higher chance of having had a significant ferritin rise (>95 $\mathrm{ng} / \mathrm{mL}$ ) in 72 hours of ICU admission among those who died. However, if age and gender are taken into consideration, there is a 25 times higher chance of having had a significant ferritin rise (> $95 \mathrm{ng} / \mathrm{mL}$ ) in 72 hours of ICU admission among those who died. The multivariate logistic regression of the parameters to mortality with age and gender taken into consideration is depicted (Table 4).

\section{Discussion}

Hyperchloremia can lead to chloride induced renal vasoconstriction and AKI, suppression of erythropoietin and thereby anaemia, decreased gastric motility, coagulopathy as well as reduced cardiac contractility. ${ }^{1}$ Incidence of hyperchloremia in our study was similar to that of previous literature in critically ill patients, where it varied between $20-40 \% .{ }^{15} \mathrm{We}$ analysed the chloride values using $\mathrm{ABG}$ machine as it leads to no extra cost for the patient, is reliable compared to serum estimation and is available at point of care. $^{10,11}$ Chloride is often the "forgotten electrolyte", but has immense significance as it can lead to metabolic acidosis or alkalosis. ${ }^{16}$ The deleterious effect of hyperchloremia and acidosis assumes significance due to its potential to increase pro-inflammatory markers. ${ }^{1}$ The role of CRP, ferritin and LDH in predicting COVID-19 prognosis is well established now. ${ }^{6,7}$ Therefore, we studied the correlation of hyperchloremia or rise in chloride by $>5 \mathrm{mmol} / \mathrm{L}$ to rise in CRP, ferritin, LDH within 72 hours. In our study, we did not find an association between either hyperchloremia or significant rise in chloride in 72 hours of ICU admission, with significant rise in either CRP, ferritin or LDH within that duration. The significant rise between day one and day three of CRP, ferritin, LDH and creatinine was considered as $>10 \mathrm{mg} / \mathrm{L}$, $>95 \mathrm{ng} / \mathrm{mL},>238 \mathrm{U} / \mathrm{L}$ based on a previous study. ${ }^{13}$ Hyperchloremia also increases mortality in sepsis (non-COVID-19) patients. ${ }^{17}$ Literature on septic patients had shown that rather than hyperchloremia per se, it is chloride rise in hypochloremic patients which predicts mortality.$^{18}$ Hence, we compared the rise in chloride to mortality in COVID-19 patients.

Ferritin has been described as one of the most important inflammatory markers to predict mortality in COVID-19 patients. ${ }^{19}$ The inability to find an association between the rise in chloride and rise in ferritin in our study could be explained by the different pathway of ferritin rise in 
COVID-19 patients compared to non-COVID-19 patients. ${ }^{20}$ Even though the relationship between chloride rise and IL-6, potentiating ferritin level is well known, the rise in ferritin differs in COVID-19 patients compared to other septic non-COVID-19 patients. ${ }^{20}$

In patients with acute inflammation unrelated to COVID-19, the extent of inflammation is correlating with IL-6 and CRP but not with ferritin rise. ${ }^{20}$ However, in COVID-19 patients, iron modification and therefore ferritin rise occurs much earlier in the disease process..$^{20}$ This could explain why the rise in chloride was unrelated to the rise in ferritin in our study, as the pathways of ferritin increase may be different in COVID-19 patients compared to other septic patients. ${ }^{20}$

Most of the studies in literature in COVID-19 depict an absolute cut-off value of ferritin for predicting poor outcome..$^{20,21,22}$ However, we have compared the rise in ferritin within 72 hours of ICU admission and found that there is a 25 times higher chance of having a significant rise (>95ng/mL) amongst those who died. The mechanism by which the hyper-activation of this ferritin inflammatory pathway causes cell death is known as ferroptosis. ${ }^{20,21}$ This mechanism has been described in Acute Respiratory Distress Syndrome (ARDS) patients, with findings similar to COVID-19 lung damage.

Merits of the study include that we have considered the significant increase in inflammatory markers at 72 hours to determine their effect on outcome, rather than a particular absolute value. Univariate and then multivariate logistic regression was done to analyse the effect of the rise in CRP, ferritin, LDH, chloride, creatinine to outcome. Also, it was a prospective observational study and not a retrospectively collected data. However, the study had its limitations, with a small sample size. Also, it was a single arm observational study and we did not compare the ferritin levels in those who did not have hyperchloremia.

\section{Conclusion}

Hyperchloremia or a rise in chloride by $>5 \mathrm{mmol} / \mathrm{L}$ in 72 hours of ICU admission was not associated with a significant rise in CRP, LDH, ferritin, serum creatinine or mortality in moderate-severe COVID-19 patients. If age and gender are taken into consideration, there is a 25 times higher chance of having had a significant ferritin rise (> $95 \mathrm{ng} / \mathrm{mL}$ ) in 72 hours of ICU admission among those who died.

\section{Declaration}

The authors declare no conflict of interest. The authors did not receive any financial assistance or source of funding.

\section{References}

1. Filis C, Vasileiadis I, Koutsoukou A. Hyperchloraemia in sepsis. Ann Intensive Care 2018 Mar 27; 8(1):43.

https://doi: 10.1186/s13613-018-0388-4

2. Noritomi DT, Soriano FG, Kellum JA, Cappi SB, Biselli PJ, Libório AB, Park M. Metabolic acidosis in patients with severe sepsis and septic shock: a longitudinal quantitative study. Crit Care Med 2009 Oct; 37(10):2733-9. https://doi: 10.1097/ccm.0b013e3181a59165

3. Pfortmueller CA, Uehlinger D, von Haehling $S$, Schefold JC. Serum chloride levels in critical illness-the hidden story. Intensive Care Med Exp 2018 Apr 13; 6(1):10. https://doi.org/10.1186/s40635-018-0174-5

4. Bellocq A, Suberville S, Philippe C, Bertrand F, Perez J, Fouqueray B, et al. Low environmental $\mathrm{pH}$ is responsible for the induction of nitric-oxide synthase in macrophages. Evidence for involvement of nuclear factorkappaB activation. $J$ Biol Chem. 1998; 273(9):5086-92

5. Wynants M, Vengethasamy L, Ronisz A, Meyns B, Delcroix M, Quarck R. NF-кB pathway is involved in CRP-induced effects on pulmonary arterial endothelial cells in chronic thromboembolic pulmonary hypertension. Am J Physiol Cell Mol Physiol [Internet]. 2013 Oct 4; 305(12):L934-42. https://doi.org/10.1152/ajplung.00034.2013

6. Huang I, Pranata R, Lim MA, Oehadian A, Alisjahbana B. C-reactive protein, procalcitonin, D-dimer, and ferritin in severe coronavirus disease-2019: a meta-analysis. Ther Adv Respir Dis. 2020 JanDec;14:1753466620937175. https://doi.org/10.1177/1753466620937175 
7. Poggiali E, Zaino D, Immovilli P, Rovero L, Losi G, Dacrema A, et al. Lactate dehydrogenase and C-reactive protein as predictors of respiratory failure in CoVID-19 patients. Clin Chim Acta [Internet]. 2020; 509:135-8.

https://www.sciencedirect.com/science/articl e/pii/S000989812030276X

8. R Gandhi RT, Lynch JB, del Rio C. Mild or Moderate Covid-19. N Engl J Med. 2020; 383(18): 1757-66.

https://doi.org/ 10.1056/NEJMcp2009249

PMID: 32329974

9. Makris K, Spanou L. Acute Kidney Injury: Definition, Pathophysiology and Clinical Phenotypes. Clin Biochem Rev. 2016; 37(2):85-98.

PMID: 28303073; PMCID: PMC5198510

10. Flegar-Mestrić Z, Perkov S. Comparability of point-of-care whole-blood electrolyte and substrate testing using a Stat Profile Critical Care Xpress analyzer and standard laboratory methods. Clin Chem Lab Med. 2006; 44(7):898-903.

https://doi.org/ 10.1515/CCLM.2006.148

11. Uysal E, Acar YA, Kutur A, Cevik E, Salman N, Tezel O. How reliable are electrolyte and metabolite results measured by a blood gas analyzer in the ED? Am J Emerg Med. 2016; 34(3):41924.

https://doi.org/10.1016/j.ajem.2015.11.025. Epub 2015 Nov 26

12. Neyra JA, Canepa-Escaro F, Li X, Manllo J, Adams-Huet B, Yee J, Yessayan L; Acute Kidney Injury in Critical Illness Study Group. Association of Hyperchloremia With Hospital Mortality in Critically Ill Septic Patients. Crit Care Med. 2015 Sep; 43(9):1938-44. https://doi.org/10.1097/CCM.000000000000 1161

13. Lakhani, J. D., Pandya, H., Jain, A., \& Ghadiya, S. Continuous Blood Glucose Monitoring to Determine the Glycemic Variability in Patients Having SARS CoV-2 Infection with ARDS and Its Bearing on the Severity of the Disease. Journal of Advances in Medicine and Medical Research 2020; 32(16):51-56. https://doi.org/10.9734/jammr/2020/v32i163 0629
14. Cioc A, Fodor R, Benedek O, Moldovan A, Copotoiu SM. Blood sampling as a cause of anemia in a general ICU - a pilot study. Rom $J$ Anaesth Intensive Care. 2015; 22(1):13-16.

15. Suetrong B, Pisitsak C, Boyd JH, Russell JA, Walley KR. Hyperchloremia and moderate increase in serum chloride are associated with acute kidney injury in severe sepsis and septic shock patients. Crit Care. 2016 Oct 6; 20(1):315.

https://doi.org/10.1186/s13054-016-1499-7

16. Berend K, van Hulsteijn LH, Gans RO. Chloride: the queen of electrolytes? Eur $J$ Intern Med. 2012 Apr; 23(3):203-11. https://doi.org/10.1016/j.ejim.2011.11.013 Epub 2011 Dec 21.

17. Neyra JA, Canepa-Escaro F, Li X, Manllo J, Adams-Huet B, Yee J, Yessayan L; Acute Kidney Injury in Critical Illness Study Group. Association of Hyperchloremia With Hospital Mortality in Critically Ill Septic Patients. Crit Care Med. 2015 Sep; 43(9):1938-44. https://doi.org/10.1097/CCM.000000000000 1161

18. Oh HJ, Kim SJ, Kim YC, Kim EJ, Jung IY, Oh DH, et al. An increased chloride level in hypochloremia is associated with decreased mortality in patients with severe sepsis or septic shock. Sci Rep. 2017; 7 (1):15883. https://doi.org/10.1038/s41598-017-16238-z

19. Ahmed S, Ansar Ahmed Z, Siddiqui I, Haroon Rashid N, Mansoor M, Jafri L. Evaluation of serum ferritin for prediction of severity and mortality in COVID-19- A cross sectional study. Ann Med Surg. 2021 Mar; 63:102163. https://doi.org/ 10.1016/j.amsu.2021.02.009

20. Banchini F, Cattaneo GM, Capelli P. Serum ferritin levels in inflammation: a retrospective comparative analysis between COVID-19 and emergency surgical non-COVID-19 patients. World J Emerg Surg. 2021; 16(1):9. https://doi.org/10.1186/s13017-021-00354-3

21. Gandini O, Criniti A, Ballesio L, Giglio S, Galardo G, Gianni W, Santoro L, Angeloni A, Lubrano C. Serum Ferritin is an independent risk factor for Acute Respiratory Distress Syndrome in COVID-19. J Infect. 2020 Dec; 81(6):979-997. https://doi.org/10.1016/j.jinf.2020.09.006 
Amara et al. Sri Lankan Journal of Anaesthesiology: 29(2): 95-102 (2021)

22. Faix JD. Biomarkers of sepsis. Crit Rev Clin Lab Sci. 2013; 50(1):23-36.

https://doi.org/10.3109/10408363.2013.7644

90 